15 CLINICAL FEATURES OF 1,2-DICHLOROETHANE POISONING: A REVIEW OF 59 CASES

Yu Quan Chen. Guangzhou Prevention and Treatment Centre for Occupational Diseases, Guangzhou, China

\subsection{6/oemed-2018-ICOHabstracts.1164}

Purpose The aim of this study was to summarise the features of toxication on cases of occupational subacute 1,2-dichloroethane poisoning and to evaluate the prognosis through their different patterns of clinical manifestation.

Methods In this cross sectional study, medical records of all occupational subacute 1,2- dichloroethane intoxicated patients at the Guangzhou Occupational Health Prevention and Treatment Centre, Guangdong, China from 2009 to 2015 were retrospectively reviewed. Clinical features, laboratory findings, cranial computed tomography (CT) and therapies of each case were evaluated.

Results A total of 59 patients were included for evaluation. There were 3 main clinical manifestations (1): intracranial hypertension $(n=29)$, tremor of the $\operatorname{limbs}(n=20)$, mental and behavioural disorder $(n=10)$. There were four cases of mortality while basic recovery was observed in 45 patients and 10 experienced an improvement of symptoms.

Conclusion The clinical characteristic of occupational subacute 1,2- dichloroethane poisoning is central nervous system damage. It is serious after onset, especially in intracranial hypertension patients without specific antidote. However, prompt treatment resulted in a favourable prognosis in most case.

\section{RETROSPECTIVE STUDY OF THE PROFILE OF BRAZILIANS ALCOHOL AND DRUG DEPENDENT WORKERS RECEIVING SICK LEAVE BENEFIT}

${ }^{1} \mathrm{CM}$ Galhardi*, ${ }^{1}$ RL Fregonezi, ${ }^{1}$ LFT Priester, ${ }^{2} \mathrm{AF}$ Dias Junior, ${ }^{1,2} \mathrm{LR}$ Ferreira. ${ }^{1}$ Centro Universitário das Faculdades Associadas de Ensino - FAE, São João da Boa Vista, Brazil; ${ }^{2}$ Brazilian National Security Institute

\subsection{6/oemed-2018-ICOHabstracts.1165}

Introduction Mental and behavioural disorders including chemical dependency (CD) are one of the most important causes of work absence. More than 6 million Brazilians is affected with problems associated with substance abuse. Studies suggests that alcohol and drugs have been the most prevalent and the main cause of long period work absence. The objective of this study is to analise the profile of workers with chemical dependency receiving sick leave benefits.

Method This was a restrospective study between July 2014 and July 2016. It involved 42 workers receiving temporary sick leave benefits from the National Social Security Institute (INSS) and they were submitted to structured analysis for the data collection, including: sex, age, occupation, international classification of diseases (ICD), work absence, readmissions, time of chemical dependence and current employment status. Results Most of the chemical dependents were: male (40), with mean age of 37 years (ranging from 21-63 years); $30.9 \%$ traders, $28.6 \%$ construction workers, $16.7 \%$ cleaning and public safety workers, 9.5\% drivers, 9.5\% rural workers and $4.8 \%$ general production workers; mean time of dependence $=16$ years (ranging from $1-48$ years). Most prevalent disorders: multiple drug (ICD-F19\%-69\%), alcohol related (ICDF10\%-26.2\%) and cocaine related (ICD-F14 4.8\%), with 93\% associated with smoking; mean time work absence was 79 days; $57 \%$ were employed.

Discussion The results showed the worker's profile with CD, demonstrating the relevance of alcohol and drug abuse in this population and present to companies to take preventive measures related with work absence, and health promotion through the reduction of CD's prevalence at work. The results of the analysis are consistent with findings from the literature.

\section{DIAGNOSTICS BIOMARKERS OF MALIGNANT PLEURAL MESOTHELIOMA}

${ }^{1} \mathrm{C}$ Jiménez ${ }^{*},{ }^{2} \mathrm{G}$ Aguilar, ${ }^{2} \mathrm{C}$ Juárez, ${ }^{3} \mathrm{G}$ Johnen, ${ }^{3}$ I Raiko, ${ }^{1} \mathrm{E}$ Calderón, ${ }^{1} \mathrm{~L}$ Acosta. ${ }^{1}$ Research Centre and Advanced Studies of the National Polytechnic Institute, México City, México; ${ }^{2}$ Mexican Social Security Institute, México City, México; ${ }^{3}$ Institute for Prevention and Occupational Medicine, Bochum, Germany

\subsection{6/oemed-2018-ICOHabstracts.1166}

Introduction Malignant Pleural Mesothelioma (MPM) is an aggressive cancer caused by occupational, environmental and indirect exposure to asbestos, material that some countries have already prohibited. Survival is less than 1 year. Diagnosis is currently a challenge and the search for early, single or combined diagnostic biomarkers continues to be performed on non-invasive samples.

Methods A case-control study was conducted in 166 cases and 394 controls recruited from 2007-2016 at the Mexican Social Security Institute. Men and Women were included. The plasma concentration of mesothelin, calretinin and megakaryocyte potentiating factor (MPF) was determined by Enzymelinked ImmunoSorbent Assay (ELISA) in each sample. Each participant has general data, socio-economic, occupational exposure, environmental, etc. Data were analysed using STATA.

Results The median of mesothelin in cases and controls was 2.25 and $0.55 \mathrm{nM} / \mathrm{ml}$ respectively; For MPF of 50.80 and $17.13 \mathrm{ng} / \mathrm{ml}$ and for calretinin of 1.05 and $0.14 \mathrm{ng} / \mathrm{ml}$. Mesothelin had a sensitivity of $80.12 \%$ and specificity of $91.12 \%$ $(\mathrm{AUC}=0.9175) ; \quad \mathrm{MPF} \quad$ with $78.18 \%$ and $88.78 \%$ $(\mathrm{AUC}=0.9009)$ and calretinin with $79.88 \%$ and $81.68 \%$ (AUC $=0.8791)$, respectively.

Discussion Mesothelin is the most promising molecule to be used as a diagnostic biomarker of (MPM) because it offers better specificity alone or in combination with another biomarker. However, it will be necessary searching for other molecular levels of biomarkers that offer, together with mesothelin, the capability to increase the sensitivity and specificity of a non-invasive diagnostic method.

\section{HYDROFLUORIC ACID - EFFECTS OF SKIN DECONTAMINATION ON THE BIOAVAILABILITY OF FLUORIDE}

Kathrin Dennerlein*, Theresa Hahn, Thomas Göen, Hans Drexler, Sonja Kilo. Institute of Occupational Medicine, Friedrich-Alexander-Universität Erlangen, Germany

\subsection{6/oemed-2018-ICOHabstracts.1167}

Introduction After dermal contact to occupational hazardous substances the cleaning of exposed skin areas is an important first aid measure to reduce adverse health effects. Due to possible severe systemic intoxication following dermal exposure to 